\title{
Alcohol outlet density and university student drinking: A National study
}

\author{
Kypros Kypri*1,2 \\ Melanie L. Bell ${ }^{3}$ \\ Geoff C. Hay ${ }^{2}$ \\ Joanne Baxter ${ }^{4}$
}

\begin{abstract}
${ }^{1}$ School of Medicine and Public Health, University of Newcastle, Australia
${ }^{2}$ Injury Prevention Research Unit, Department of Preventive and Social Medicine University of Otago, New Zealand

${ }^{3}$ Department of Preventive and Social Medicine, University of Otago, New Zealand ${ }^{4}$ Ngai Tahu Maori Health Research Centre, Department of Preventive and Social Medicine University of Otago, New Zealand
\end{abstract}

For correspondence:

Kyp Kypri

School of Medicine and Public Health

University of Newcastle

Callaghan 2308 NSW Australia

Tel: +61 24913 8231, Fax: +61 24913 8148, kypros.kypri@newcastle.edu.au

Word count: 3,490 (Abstract: 214) 


\begin{abstract}
Aims: To examine the geographic density of alcohol outlets and associations with drinking levels and related problems among university students.

Design: Cross-sectional survey study using geospatial data, with campus-level and individual-level analyses.
\end{abstract}

Participants: 2,550 students (mean age $20.2,60 \%$ women) at six university campuses in New Zealand (63\% response).

Measurements: Counts of alcohol outlets within $3 \mathrm{~km}$ of each campus were tested for their non-parametric correlation with aggregated campus drinking levels and related problems. Generalized estimating equations were used to model the relation between outlet counts within $1 \mathrm{~km}$ and $3 \mathrm{~km}$ of student residences and individual drinking levels/problems, with control for gender, age, ethnicity and high school binge drinking frequency, and adjustment for campus-level clustering.

Findings: Correlations for campus-level data were $0.77(\mathrm{p}=0.07)$ for drinking and personal problems, and $0.31(\mathrm{p}=0.54)$ for secondhand effects. There were consistent significant associations of both on- and off-license outlet densities with all outcomes in student-level adjusted models. Effects were largest for $1 \mathrm{~km}$ densities and offlicense outlets.

Conclusions: There are positive associations between alcohol outlet density and individual drinking and related problems. Associations remain after controlling for demographic variables and pre-university drinking, i.e., the associations are unlikely to be due to self-selection effects. Increasing alcohol outlet density, and particularly off-licenses, may increase alcohol-related harm among university students.

Keywords: alcohol, outlet density, students, university, college 
There is a growing research literature reporting evidence of a positive association between the geographic density of on- and off-license alcohol outlets and the incidence of a range of alcohol-related harms [1-8]. Most of the studies use crosssectional data and include statistical control of various confounders, including social deprivation and other retail activity. Three longitudinal studies have demonstrated a temporal dependence. In the state of California, changes in alcohol outlet densities in zip code areas were positively associated with the incidence of hospital discharges for violent assault over a six year period [9]. In Los Angeles County, gonorrhea incidence rates were positively associated with outlet density [10], while in Norway, changes in outlet density were associated with the incidence of violence investigated by police [11].

Implicit in the conceptual models underlying research in this area are mediating variables representing the availability and promotion of alcohol, and drinking to intoxication or impairment. These have typically not been measured and analysed as mediating variables in studies conducted thus far. These variables constitute links in a supposed causal chain, in which outlet density is thought to affect drink prices and the promotion of alcohol via competition (higher density producing more competition), while levels of physical availability, i.e., non-monetary acquisition cost [12] are reduced with higher density. Low prices, promotion, and increased availability are thereby assumed to increase alcohol consumption, and in particular, the incidence and/or severity of drinking to intoxication, which in turn increases the risk of acute problems, such as injury.

It should be noted that increased alcohol outlet density may plausibly cause increases in violence without necessarily affecting consumption levels, because concentrations of outlets have been found to attract anti-social individuals [13]. In 
addition, clusters of outlets increase interactions between young males, thereby increasing the risk of physical confrontation [14]. In what has been a largely empirical research endeavour to date, there have been recent efforts to integrate criminological theory with alcohol availability theory by way of explaining the many positive associations between outlet density and harm reported in the literature (see Livingston et al[15] for a review).

Much previous research acknowledges that other factors affect the incidence of drinking to intoxication, and the risk of acute outcomes. These variables include social deprivation and transportation patterns $[3,16]$. In two recent US studies, alcohol outlets were found to be more prevalent in poorer areas than in wealthy areas, despite there being lower per capita consumption in poorer communities $[17,18]$. Notably, social deprivation has often been shown to account for much of the variation in the incidence of certain acute outcomes such as violent assault [19].

Because outlet density studies typically rely on administrative data (e.g., traffic crash reports and liquor licensing registers), there is little literature concerning the supposed mediators of the outlet density_-harm relationship, i.e., changes in availability and promotion, and in drinking behaviour, neither of which are recorded in administrative datasets. In addition, reliance on administrative data means that the effects of social selection [20] cannot be controlled for statistically except at the ecological level (e.g., via census tract information). It is possible, for example, that people select the places they live, at least partly, on the basis of their drinking preferences: heavy drinkers preferring areas with access to plenty of alcohol outlets, light drinkers and abstainers preferring quieter areas. The observed associations may therefore not completely reflect the supposed causal chain described above, but would instead be, at least partly, the product of selection processes. 
A few studies have examined associations between various physical availability measures, including outlet density, and individual drinking reported in surveys. The results of these studies have been mixed. Using multilevel modelling, Scribner and colleagues found that neighbourhood outlet density, but not individual measures of access (e.g., distance to the nearest outlet), was associated with consumption levels in New Orleans [21]. Using a similar analytical approach in a study of Californian residents, Pollack et al. found that neighbourhood outlet density and the proximity of outlets to survey respondents' homes was unrelated to individual consumption levels after controlling for deprivation [18]. In an ecologic (i.e., campus level) — rather than multilevel — analysis, Weitzman et al. found a modest positive association between the number of outlets within two miles of college campuses $(n=8)$ and college binge drinking rates [22]. In the only non-US study examining this relationship, Kuntsche and Kuendig used multilevel modelling of survey data, finding a main effect of outlet density on drinking and drunkenness among Swiss ninth graders [23].

The aim of this study was to examine the association between alcohol outlet density, drinking levels, and harm, with control for individual drinking predispositions. The study population was students from six university campuses in New Zealand. We attempted to replicate the ecologic (i.e., campus-level) analysis by Weitzman et al.[22], and to extend it by modelling (at the individual level) students' drinking levels and related problems, with their demographic characteristics and a measure of high school binge drinking, used to control for selection effects.

\section{METHODS}

\section{Setting}


In 2006 New Zealand had a population of 4 million including 491,000 students participating in tertiary education, with 333,000 of them at one of the country's eight universities [24]. We invited all eight universities — which include 10 campuses — to participate, and five of them, including six campuses, agreed.

\section{Participants and procedure}

The sample was 1,983 full-time students aged 17-25 years, from the six campuses. Sample size estimates were based on our previous work [25], and assumed a hazardous drinking prevalence estimate of $60 \%$ with a $95 \%$ confidence interval of $+/-$ $5.6 \%$, and a response rate of $70 \%$, conservatively estimated from pilot research [25]. Random samples of full-time undergraduates aged 17-25 years were drawn from campus enrolment lists separately for Māori (the indigenous people of New Zealand) and non-Māori students. Māori comprise 15\% of the New Zealand population and $7.5 \%$ of university students [24]. We sought to invite 430 Māori and 430 non-Māori students from each campus in order to maximize the explanatory power of the study for Māori, who have traditionally been poorly served by population surveys [26], despite bearing a considerably greater burden of alcohol-related harm than non-Māori [27]. On several campuses, there were fewer than 430 Māori students, in which case, we invited all of them to participate. University survey response rates varied from $53 \%$ to $72 \%$ ( $63 \%$ overall). Response rates did not vary by age and gender, but Māori students were somewhat less likely to participate (60\%) than non-Māori students $(65 \% ; p=0.03)$.

The recruitment procedures, as used in a previous survey, have been described in detail elsewhere $[28,29]$. In summary, each member of the sample received a personalised letter and an e-mail inviting them to complete an on-line health survey. 
The e-mail contained a hyperlink to the questionnaire. Up to three e-mail reminder messages were sent to non-respondents. The survey was conducted in the first semester of the 2005 academic year.

\section{Measures}

The questionnaire included items from the following domains: fruit and vegetable consumption, physical activity, smoking, symptoms of depression, perceptions of local drinking environments, perceived drinking norms, alcohol use, personal alcoholrelated problems, effects of other students' drinking (secondhand effects), and demographic characteristics (age, ethnicity, type of residence). Items from the last four of the listed domains were used in this study. The questionnaire can be viewed at http://ipru3.otago.ac.nz/hdpdemo/ns2005/ .

Alcohol consumption. Respondents were asked to indicate the number of days they drank alcohol in a typical four week period, and the typical number of drinks they consumed per occasion. Men were asked to indicate the number of days in which they consumed six or more standard drinks ( $\geq 60 \mathrm{~g}$ ethanol). Women were asked to indicate the number of days in which they consumed four or more standard drinks $(\geq 40 \mathrm{~g}$ ethanol). Images of standard drinks, their definitions, and examples of typical beverage alcohol contents were provided for reference. All response options were provided via drop-down menus with pre-defined values.

Alcohol-related personal problems. Respondents were presented with the Alcohol Problems Scale (APS) [30], a 14-item checklist of problems experienced due to their 
drinking (e.g., 'a sexual encounter you later regretted') in the preceding four weeks. Possible responses were yes, no, and prefer not to answer (coded as missing).

Second-hand effects (SHE). Respondents were presented with a list of 11 negative consequences [31] they experienced as a result of other students' drinking (e.g., 'being pushed, hit, or otherwise assaulted') in the preceding four weeks. Possible responses were none, once, 2-3 times, 4 or more times, and prefer not to answer (coded as missing).

Binge drinking in high school. Respondents were asked to indicate the frequency of their consuming more than $4 / 6$ drinks (females/males) per occasion in their last year of high school. Response options ranged from never to daily.

Alcohol outlet density. A list of on-license (pubs, bars, clubs, restaurants) and offlicense (bottle shops, supermarkets, convenience stores) alcohol outlets that were operational in the first half of 2005 (i.e., in the months prior to and during the time of the survey), was obtained from the Ministry of Justice. All outlet locations were successfully geocoded using GeoStan [32]. Of the 2,304 outlets, 2012 (87\%) were able to be precisely located. The remaining outlets could only be located at the street level due to incomplete address information in the outlet data. Outlets located within 1 $\mathrm{km}$ and $3 \mathrm{~km}$ of each university's clock tower (an approximate "centre of campus") or central administration building were selected and mapped using ArcMap [33]. The number of outlets in each circle served as the outlet density measure in ecologic analyses described below. 
The term-time residential address given at the time of enrolment by each respondent was also mapped. For respondents whose addresses were within $25 \mathrm{~km}$ of the university clock tower or central administration building, the number of alcohol outlets within $1 \mathrm{~km}$ and $3 \mathrm{~km}$ of their home address was used as an explanatory variable in student level models (described below).

\section{Analyses}

We considered five outcome measures of drinking and alcohol-related harm: 4-week drinking frequency (range 0-28), 4-week quantity per day (in standard drinks, $10 \mathrm{~g}$ ethanol), 4-week binge frequency (range 0-28), Alcohol Problem Scale score (range $0-14)$ and the sum of secondhand effects (range 0-44), which accounts for the frequency of the effects. Given the similarity of findings for the three drinking measures, we report only the second of them, along with the two problems measures.

Ecologic analyses. We replicated the ecologic analysis performed by Weitzman et al. [22], by using Spearman rank correlation of the density of alcohol outlets within $3 \mathrm{~km}$ of each of the six campuses, and the measures of drinking and alcohol-related harm aggregated at the campus level. This was done separately for on- and off-license outlets, and then for both combined. This analysis was conducted with students who resided within $3 \mathrm{~km}$ of campus, and again with all students, irrespective of their address.

Individual-level models. The second approach assessed alcohol-related harm outcomes on a student level, by finding the 1 and $3 \mathrm{~km}$ outlet (on and off) density for each student, with respect to their self-reported residence. The analyses were 
restricted to those students who lived within $25 \mathrm{~km}$ of the campus centre. Clustering by campus was accounted for by using generalized estimating equations (GEE) [34] with the negative binomial distribution, as all of the outcomes were over-dispersed counts.

Sex, age, ethnicity (NZ European, Māori, Chinese and Other, which includes Pacific Island, Indian and missing) and high school binge drinking (binary, with a cutoff of once every two weeks and more being defined as "yes") were included in the model as well. Oversampling of Māori was taken into account by weighting according to sample weights. This analysis was restricted to respondents who lived within $25 \mathrm{~km}$ of the university clock tower. We took this measure because in some cases the home address provided to us by universities appeared to be an out-of-term location, such as a parent's home in another part of the country. By excluding such cases we hoped to reduce the likelihood of classification error. All statistical analyses were performed using the statistical software SAS [35].

\section{RESULTS}

\section{Respondent demographic characteristics and high-school drinking}

The demographic characteristics of respondents from each campus are presented in Table 1. It should be noted that the ethnic distributions varied considerably by campus. Ethnicity was controlled for in the student level models described below.

There were 2,550 students with survey data, 95 of whom had insufficient or missing address data for accurate map coordinates to be calculated and so were not included in the analysis. For the ecologic analyses, 1,022 students who lived within 3 $\mathrm{km}$ of the campus centre were included. A further 961 students lived between 3 and $25 \mathrm{~km}$ from campus and were included in the student level analyses. A further 472 
students gave addresses that were more than $25 \mathrm{~km}$ away from the centre of campus, and were not included in the analysis, given the possibility that the addresses provided actually reflected the location of their out of term residence, often their parents' home.

There were large differences between campuses, in the proportion of students who reported frequent binge drinking in high school (range $23 \%$ to $51 \%$, p $<0.001$ ). Table 1 shows that across the six campus areas, there were 2,032 outlets (median per campus: 234), including 515 off-license, and 1,517 on-license outlets. There was marked variation in the number of alcohol outlets near campuses (range: 1 to 507).

$<$ Table 1>

\section{Ecologic analyses}

For the overall measure of $3 \mathrm{~km}$ outlet density (i.e., for on- and off-licenses together), Spearman rank correlation coefficients for drinking days per 4-week period, drinks per drinking day, binge episodes per 4-week period, and the Alcohol Problems Scale were each $0.77(p=0.07)$. For secondhand effects, the coefficient was $0.31(p=0.54)$. Identical results were observed for on-license outlet density. It should be noted that coefficients and p-values were identical across the first four measures because campuses were ranked in the same order for those measures. Figure 1 presents scatter plots representing density measures for all on- and off-license outlets and (a) drinks per drinking day, (b) Alcohol Problems Scale, and (c) secondhand effects, in the six university campus areas, for students who resided within $3 \mathrm{~km}$ of campus. The relationships were weaker $(\mathrm{r}=0.43, \mathrm{p}=0.42)$ when all students (i.e., irrespective of where they lived) were included. 


\section{Student level analysis}

Findings for the three drinking variables: drinking frequency, drinks per typical occasion, and binge frequency, were very similar. Accordingly, in student level models, only one of these, drinks per drinking day, was included, along with the two problems measures. There were strong associations for both on- and off-license outlet densities with all three outcomes. The estimates for the entire model for $3 \mathrm{~km}$ offlicense outlets are presented in Table 2.

$<$ Table 2>

Table 2 shows that outlet density was associated with drinking levels and alcoholrelated harm. Males drank more than females and experienced more alcohol related problems. Each of the outcomes decreased with age. Relative to students of New Zealand European ethnicity students of Chinese or other ethnicity had lower estimates. There was no evidence for any of the outcomes of a significant difference (p-values 0.27 to 0.65 ) between Māori and New Zealand European students.

In Table 3, the rate ratios for the density parameters for on- and off-license outlets are presented. Notably, the off-license outlet density effect sizes for the three outcomes were larger, in each case, than those for on-license density. The effects in all cases were stronger for the $1 \mathrm{~km}$ densities than for the $3 \mathrm{~km}$ densities.

$<$ Table 3>

\section{Outlet density effect sizes}


The outlet density effect sizes may be interpreted as follows, with reference to Table 3. For each additional 10 off-license outlets within $1 \mathrm{~km}$ of respondents' homes, respondents consumed, on average, 1.090 (95\% CI: 1.020, 1.164) times as many drinks per drinking day, had $1.107(95 \%$ CI: 1.068, 1.147) times as many alcoholrelated problems, and experienced 1.133 (95\% CI: 1.035, 1.240) times as many secondhand effects. In a national university student population of 333,000 , in a given four week period, each additional off-license alcohol outlet within $1 \mathrm{~km}$ of respondents' residences would therefore be associated with an estimated 5570 more alcohol-related problems among drinkers (e.g., blackouts or episodes of physical aggression), and 10,130 additional secondhand effects (e.g., being insulted or humiliated, or having property damaged). These estimates were produced with the formula: Median outcome value $\times$ Population $\mathrm{N} \times$ rate ratio -1 .

\section{Selection effects}

Comparing unadjusted estimates to adjusted estimates (Table 3), it is evident that adjustment decreased the estimates, substantially in some cases. It appears that this was mainly driven by the propensity to drink variable, i.e., whether respondents were frequent binge drinkers in high school. In adjusted models, respondents who reported binge drinking fortnightly or more often in high school, had nearly twice as many drinks per typical drinking occasion as those who did not binge drink frequently in high school.

\section{DISCUSSION}

There was considerable variation in the number of alcohol outlets in the vicinity of university campuses. The results of the ecologic analysis broadly replicated those of 
the US study by Weitzman and colleagues [22], though p-values were larger, possibly due to the smaller number of campuses. The small number of campuses limits our ability to make strong inferences about associations. The dramatic contrasts in physical availability of alcohol around campuses are, however, worthy of note. If campus E — which has extremely high availability — is excluded, there is a steep positive association between the number of outlets and drinks per student, though it should be noted that campus B students drank less than those at campus C, despite being exposed to considerably greater availability. The relationship for problems is less compelling, campuses B and E having fewer problems per student than campuses with greater availability. These differences potentially reflect variance in the drinking propensities of students at the various campuses, i.e., what drinking habits they bring to university. For this reason, a capacity to account for individual variance within contextual units is required in analytic models.

The student level models, which used student addresses as the locus of enquiry, showed consistently positive associations between outlet densities and the outcome variables. High school binge drinking was the strongest predictor of consumption and problems, but when this was controlled in multivariate analyses, outlet density effects remained. Effects were considerably stronger for off-license outlets (e.g., supermarkets and liquor stores) than for on-license outlets.

Strengths of the study include the good survey response rate ( $63 \%$ overall). A previous study with data from one of the campuses involved in the present study, showed that error in estimating drinking levels and alcohol-related problems arising from non-response is likely to be small if the response was around 65\% [29]. The web-based survey administration is also an advantage in light of findings showing greater disclosure of risk behaviour, including binge drinking, via computers versus 
pen-and-paper format [36]. A further strength is the control for selection effects. The results suggest that students who were heavy drinkers in high school tended to cluster in certain universities. The effect of this clustering has to be accounted for when attempting to identify possible environmental influences on drinking, such as physical availability. It should be noted that our measure of high-school binge drinking, along with demographic variables, may not have completely controlled for this effect.

Other limitations include the possibility of classification error, resulting from uncertainty that the residential address in the enrolment database reflected the in-term residence of the student. Including cases in which the student did not reside at the address used in the determination of outlet density would have introduced noise, tending toward null findings.

The secondhand effects questions, though used in a number of studies, have not been published as a validated scale as far as we are aware, and its psychometric properties are unknown. Unfortunately we were not able to find a validated scale measuring the effects of others' drinking. It should be noted that if there is measurement error in the scale, this will have inflated residuals, thereby tending toward null.

There may have been error in respondents' reporting of drinking or personal alcohol-related problems. If underreporting occurred, the association may be weaker than indicated by the regression estimates. If over-reporting occurred, the converse would be true. In addition, it remains possible that our statistical analyses controlled incompletely for potential confounders and there may be confounding factors which we have not identified.

The study adds to an international literature showing that physical access to alcohol, measured by the number of outlets within walking distance of a person's 
home, is positively associated with individual drinking levels and acute harms, and that these associations are additional to the effects of those individuals' pre-existing drinking patterns. Legislators and authorities that administer liquor licensing and land use legislation should consider the probable public health risk posed by permitting increasing numbers of alcohol outlets, and in particular, off-license outlets, including bottle stores, convenience stores, and supermarkets.

\section{ACKNOWLEDGEMENTS}

The Health Research Council of New Zealand and the Alcohol Advisory Council of New Zealand funded the study. We are grateful to the participating universities for facilitating the survey, to the Ministry of Justice for providing liquor license data, and to Dr Jennie Connor, Dr Peter Whigham, and Dr Emmanuel Kuntsche for helpful comments on a draft of the paper. 


\section{REFERENCES}

1. Scribner, R. A., Mackinnon, D. P. \& Dwyer, J. H. (1994) Alcohol outlet density and motor vehicle crashes in los angeles county cities, J Stud Alcohol, $55,447-53$.

2. Scribner, R. A., Cohen, D. A. \& Farley, T. A. (1998) A geographic relation between alcohol availability and gonorrhea rates, Sex Transm Dis, 25, 544-8.

3. Gruenewald, P. J., Freisthler, B., Remer, L., Lascala, E. A. \& Treno, A. (2006) Ecological models of alcohol outlets and violent assaults: Crime potentials and geospatial analysis, Addiction, 101, 666-77.

4. Freisthler, B., Needell, B. \& Gruenewald, P. J. (2005) Is the physical availability of alcohol and illicit drugs related to neighborhood rates of child maltreatment?, Child Abuse Negl, 29, 1049-1060.

5. Donnelly, N., Poynton, S., Weatherburn, D., Bamford, E. \& Nottage, J. (2006) Liquor outlet concentrtions and alcohol-related neighbourhood problems., Alcohol Studies Bulletin, 8.

6. Gorman, D. M., Speer, P. W., Gruenewald, P. J. \& Labouvie, E. W. (2001) Spatial dynamics of alcohol availability, neighborhood structure and violent crime, J Stud Alcohol, 62, 628-36.

7. Gorman, D. M., Zhu, L. \& Horel, S. (2005) Drug 'hot-spots', alcohol availability and violence, Drug Alcohol Rev, 24, 507-13.

8. Lascala, E. A., Johnson, F. W. \& Gruenewald, P. J. (2001) Neighborhood characteristics of alcohol-related pedestrian injury collisions: A geostatistical analysis, Prev Sci, 2, 123-34.

9. Gruenewald, P. J. \& Remer, L. (2006) Changes in outlet densities affect violence rates, Alcohol Clin Exp Res, 30, 1184-93.

10. Cohen, D. A., Ghosh-Dastidar, B., Scribner, R. et al. (2006) Alcohol outlets, gonorrhea, and the los angeles civil unrest: A longitudinal analysis, Soc Sci Med.

11. Norstrom, T. (2000) Outlet density and criminal violence in norway, 19601995, J Stud Alcohol, 61, 907-11.

12. Stockwell, T. \& Gruenewald, P. (2001) Controls on the physical availability of alcohol, in: N. Heather, T. J. P. T. S. (Ed.) International handbook of alcohol dependence and problems (New York, Wiley).

13. Gruenewald, P. J. (2007) The spatial ecology of alcohol problems: Niche theory and assortative drinking, Addiction, 102, 870-8.

14. Homel, R., Tomsen, S. \& Thommeny, J. (1992) Public drinking and violence: Not just an alcohol problem, Journal of Drug Issues, 22, 679-697.

15. Livingston, M., Chikritzhs, T. \& Room, R. (2007) Changing the density of alcohol outlets to reduce alcohol-related problems, Drug Alcohol Rev, 26, 55766.

16. Gruenewald, P. J., Mitchell, P. R. \& Treno, A. J. (1996) Drinking and driving: Drinking patterns and drinking problems, Addiction, 91, 1637-49.

17. Romley, J. A., Cohen, D., Ringel, J. \& Sturm, R. (2007) Alcohol and environmental justice: The density of liquor stores and bars in urban neighborhoods in the united states, $J$ Stud Alcohol Drugs, 68, 48-55.

18. Pollack, C. E., Cubbin, C., Ahn, D. \& Winkleby, M. (2005) Neighbourhood deprivation and alcohol consumption: Does the availability of alcohol play a role?, Int J Epidemiol, 34, 772-80. 
19. Lipton, R. \& Gruenewald, P. (2002) The spatial dynamics of violence and alcohol outlets, J Stud Alcohol, 63, 187-95.

20. Oakes, J. M. (2004) The (mis)estimation of neighborhood effects: Causal inference for a practicable social epidemiology, Soc Sci Med, 58, 1929-52.

21. Scribner, R. A., Cohen, D. A. \& Fisher, W. (2000) Evidence of a structural effect for alcohol outlet density: A multilevel analysis, Alcohol Clin Exp Res, 24, 188-95.

22. Weitzman, E. R., Folkman, A., Folkman, M. P. \& Wechsler, H. (2003) The relationship of alcohol outlet density to heavy and frequent drinking and drinking-related problems among college students at eight universities, Health \& Place, 9, 1-6.

23. Kuntsche, E. N. \& Kuendig, H. (2005) Do school surroundings matter? Alcohol outlet density, perception of adolescent drinking in public, and adolescent alcohol use, Addict Behav, 30, 151-8.

24. Ministry of Education (2007) Education counts http://educationcounts.Edcentre.Govt.Nz/statistics/tertiary/index.Html accessed 31 may 2007 (Ministry of Education, New Zealand Government).

25. Kypri, K., Stephenson, S. C. R. \& Langley, J. (2005) Episode-centred analysis of drinking to intoxication in university students, Alcohol \& Alcoholism, 40, 447-452.

26. Wellington School of Medicine and Health Sciences. (2002) Mana whakamarama- equal explanatory power: Maori and non-maori sample size in national health surveys, pp. 1-22 (Wellington, Public Health Intelligence).

27. Connor, J., Broad, J. B., Jackson, R., Vander Hoorn, S. \& Rehm, J. (2004) The burden of death, disease and disability due to alcohol in new zealand $A L A C$ Occasional Publication No. 23 (Wellington, Alcohol Advisory Council).

28. Kypri, K., Gallagher, S. J. \& Cashell-Smith, M. L. (2004) An internet survey method for college student drinking research, Drug and Alcohol Dependence, 76, 45-53.

29. Kypri, K., Stephenson, S. C. R. \& Langley, J. D. (2004) Assessment of nonresponse error in an internet survey of alcohol use, Alcoholism Clinical and Experimental Research, 28, 630-4.

30. Mcgee, R. \& Kypri, K. (2004) Alcohol-related problems experienced by university students in new zealand, Australian and New Zealand Journal of Public Health, 28, 321-323.

31. Langley, J. D., Kypri, K. \& Stephenson, S. (2003) Secondhand effects of alcohol use among university students: Computerised survey, British Medical Journal, 327, 1023-4.

32. Critchlow Limited (2006) Geostan map [computer program] (Christchurch, Critchlow Limited).

33. Research Institute Inc. (Esri) (1995-2007) Arcmap [computer program]. (USA, Environmental Systems).

34. Zeger, S. L. \& Liang, K. Y. (1986) Longitudinal data analysis for discrete and continuous outcomes, Biometrics, 42, 121-30.

35. Sas Institute Inc (2004) Sas 9.1 help and documentation (Cary, NC, SAS Institute Inc.).

36. Turner, C. F., Ku, L., Rogers, S. M. et al. (1998) Adolescent sexual behaviour, drug use, and violence: Increased reporting with computer survey technology, Science, 280, 867-873. 
TABLE 1-Respondent demographics, summary outcome measures and campus area outlet densities

\begin{tabular}{|c|c|c|c|c|c|c|c|}
\hline & \multicolumn{6}{|c|}{ Campus area } & \multirow[b]{2}{*}{$\begin{array}{l}\text { Overall } \\
(n=1981)\end{array}$} \\
\hline & $\begin{array}{c}\mathbf{A} \\
(\mathrm{n}=192)\end{array}$ & $\begin{array}{c}\text { B } \\
(n=210)\end{array}$ & $\begin{array}{c}\mathbf{C} \\
(n=244)\end{array}$ & $\begin{array}{c}\mathbf{D} \\
(\mathrm{n}=603)\end{array}$ & $\begin{array}{c}\mathbf{E} \\
(n=451)\end{array}$ & $\begin{array}{c}\mathbf{F} \\
(n=283)\end{array}$ & \\
\hline Age (years) $\dagger$ & $\begin{array}{c}21 \\
(20,22)\end{array}$ & $\begin{array}{c}20 \\
(19,22)\end{array}$ & $\begin{array}{c}20 \\
(19,21)\end{array}$ & $\begin{array}{c}20 \\
(19,21)\end{array}$ & $\begin{array}{c}20 \\
(19,21)\end{array}$ & $\begin{array}{c}20 \\
(19,22)\end{array}$ & $\begin{array}{c}20 \\
(19,21)\end{array}$ \\
\hline $\begin{array}{l}\text { Gender, \% } \\
\text { Females } \\
\text { Males }\end{array}$ & $\begin{array}{l}57 \\
43\end{array}$ & $\begin{array}{l}51 \\
49\end{array}$ & $\begin{array}{l}59 \\
41\end{array}$ & $\begin{array}{l}63 \\
37\end{array}$ & $\begin{array}{l}62 \\
38\end{array}$ & $\begin{array}{l}63 \\
37\end{array}$ & $\begin{array}{l}60 \\
40\end{array}$ \\
\hline $\begin{array}{l}\text { Ethnicity, \% } \\
\text { New Zealand European } \\
\text { New Zealand Māori* } \\
\text { Chinese } \\
\text { Other }\end{array}$ & $\begin{array}{c}45 \\
2 \\
46 \\
7\end{array}$ & $\begin{array}{l}34 \\
10 \\
40 \\
16\end{array}$ & $\begin{array}{l}44 \\
32 \\
14 \\
10\end{array}$ & $\begin{array}{c}44 \\
42 \\
4 \\
10\end{array}$ & $\begin{array}{c}37 \\
35 \\
9 \\
19\end{array}$ & $\begin{array}{l}41 \\
34 \\
13 \\
12\end{array}$ & $\begin{array}{l}41 \\
31 \\
15 \\
13\end{array}$ \\
\hline $\begin{array}{l}\text { Frequent binge drinking in } \\
\text { high school, \% }\end{array}$ & 35 & 23 & 41 & 51 & 43 & 21 & 42 \\
\hline $\begin{array}{l}\text { Drinks per typical drinking } \\
\text { day } \dagger\end{array}$ & $\begin{array}{c}2 \\
(0,6)\end{array}$ & $\begin{array}{c}2 \\
(1,4)\end{array}$ & $\begin{array}{c}5 \\
(2,9.5)\end{array}$ & $\begin{array}{c}7 \\
(4,10)\end{array}$ & $\begin{array}{c}4 \\
(2,8)\end{array}$ & $\begin{array}{c}2 \\
(0,5)\end{array}$ & $\begin{array}{c}5 \\
(2,8)\end{array}$ \\
\hline $\begin{array}{l}\text { Alcohol Problem Scale } \dagger \\
\text { (possible range } 0-14 \text { ) }\end{array}$ & $\begin{array}{c}0 \\
(0,2)\end{array}$ & $\begin{array}{c}0 \\
(0,1)\end{array}$ & $\begin{array}{c}1 \\
(0,3)\end{array}$ & $\begin{array}{c}2 \\
(0,3)\end{array}$ & $\begin{array}{c}1 \\
(0,3)\end{array}$ & $\begin{array}{c}0 \\
(0,2)\end{array}$ & $\begin{array}{c}1 \\
(0,3)\end{array}$ \\
\hline $\begin{array}{l}\text { Secondhand effects } \dagger \\
\text { (possible range } 0-44 \text { ) }\end{array}$ & $\begin{array}{c}1 \\
(0,3)\end{array}$ & $\begin{array}{c}0 \\
(0,2)\end{array}$ & $\begin{array}{c}1 \\
(0,3)\end{array}$ & $\begin{array}{c}3 \\
(1,5)\end{array}$ & $\begin{array}{c}1 \\
(0,4)\end{array}$ & $\begin{array}{c}1 \\
(0,3)\end{array}$ & $\begin{array}{c}2 \\
(0,4)\end{array}$ \\
\hline $\begin{array}{l}\text { Campus area outlet } \\
\text { density }(3 \mathrm{~km}), \mathrm{N} \dagger \dagger \\
\text { On-license } \\
\text { Off-license } \\
\text { All licenses }\end{array}$ & $\begin{array}{l}1 \\
0 \\
1\end{array}$ & $\begin{array}{l}52 \\
23 \\
75\end{array}$ & $\begin{array}{l}8 \\
1 \\
9\end{array}$ & $\begin{array}{c}176 \\
43 \\
219\end{array}$ & $\begin{array}{l}407 \\
100 \\
507\end{array}$ & $\begin{array}{c}135 \\
26 \\
161\end{array}$ & $\begin{array}{c}25 \\
94 \\
119\end{array}$ \\
\hline
\end{tabular}

* Māori were oversampled † Median (Interquartile Range) $\dagger \dagger$ Median is shown for overall 
TABLE 2-Student drinking levels and alcohol-related harm by offlicense outlet density within $3 \mathbf{k m}$.*

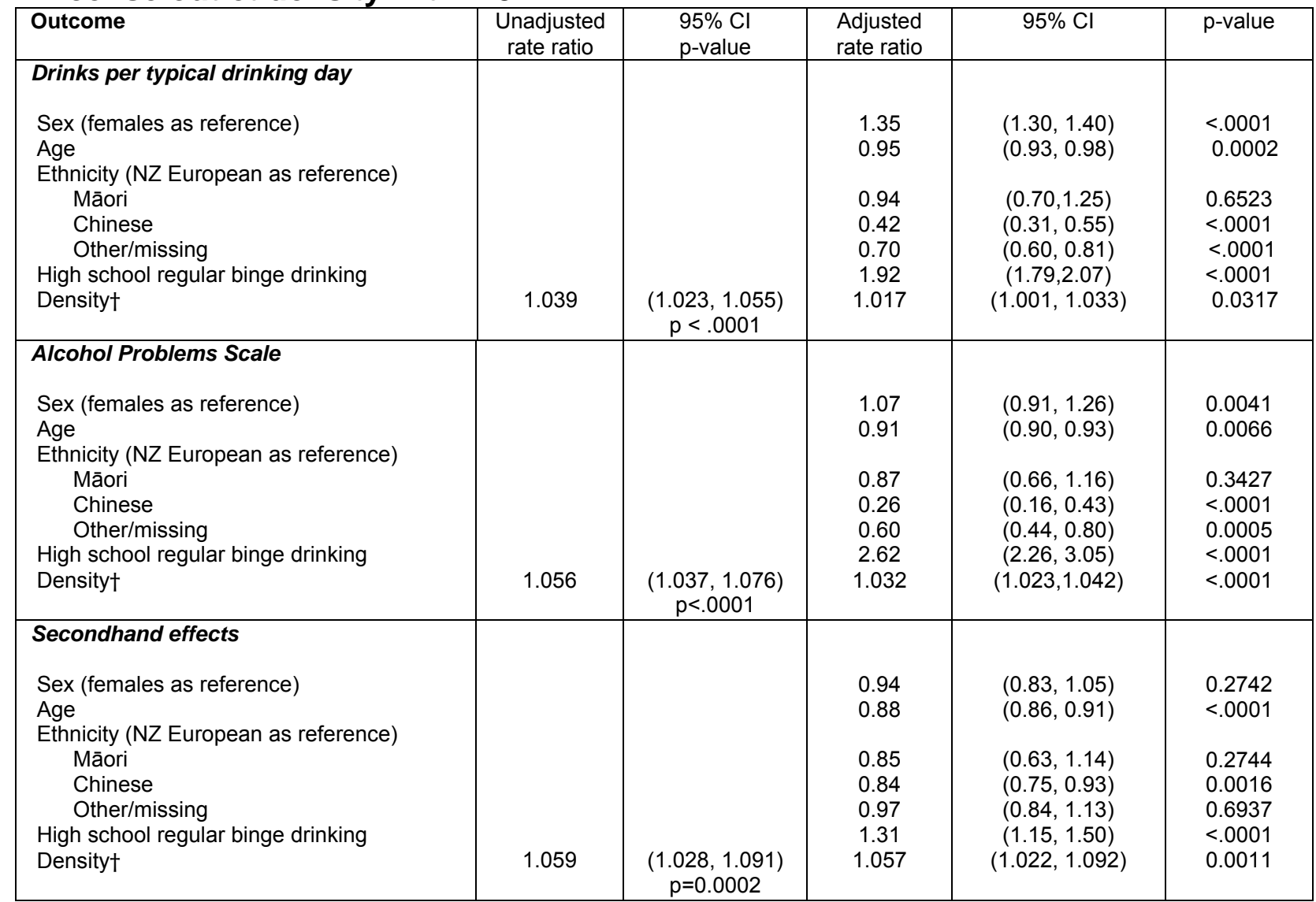

* Rate ratios were computed using a GEE negative binomial model.

† Per 10 outlets 
TABLE 3-Student level modeling of individual drinking levels and alcohol-related harm by outlet density.*

\begin{tabular}{|c|c|c|c|c|c|c|c|}
\hline Outcome & Outlet type & $\begin{array}{l}\text { Unadjusted } \\
\text { rate ratio }\end{array}$ & $95 \% \mathrm{Cl}$ & $p$ - value & $\begin{array}{c}\text { Adjusted } \dagger \\
\text { rate ratio }\end{array}$ & $95 \% \mathrm{Cl}$ & $p$-value \\
\hline $\begin{array}{l}\text { Drinks per typical } \\
\text { drinking day } \\
3 \mathrm{~km} \text { density } \\
3 \mathrm{~km} \text { density } \\
1 \mathrm{~km} \text { density } \\
1 \mathrm{~km} \text { density }\end{array}$ & $\begin{array}{l}\text { Off license } \\
\text { On license } \\
\text { Off license } \\
\text { On license }\end{array}$ & $\begin{array}{l}1.039 \\
1.010 \\
1.090 \\
1.012\end{array}$ & $\begin{array}{c}(1.023,1.055) \\
(1.004,1.016 \\
(1.020,1.164) \\
(1.006,1.019)\end{array}$ & $\begin{array}{l}<.0001 \\
0.0006 \\
0.0107 \\
0.0003\end{array}$ & $\begin{array}{l}1.017 \\
1.005 \\
1.047 \\
1.005\end{array}$ & $\begin{array}{c}(1.001,1.033) \\
(0.999,1.010) \\
(0.978,1.121) \\
(0.999,1.012\end{array}$ & $\begin{array}{l}0.0317 \\
0.0910 \\
0.1855 \\
0.1235\end{array}$ \\
\hline $\begin{array}{l}\text { Alcohol Problems } \\
\text { Scale } \\
3 \mathrm{~km} \text { density } \\
3 \mathrm{~km} \text { density } \\
1 \mathrm{~km} \text { density } \\
1 \mathrm{~km} \text { density }\end{array}$ & $\begin{array}{l}\text { Off license } \\
\text { On license } \\
\text { Off license } \\
\text { On license }\end{array}$ & $\begin{array}{l}1.056 \\
1.014 \\
1.107 \\
1.017\end{array}$ & $\begin{array}{l}(1.037,1.076) \\
(1.010,1.018) \\
(1.068,1.147) \\
(1.006,1.028)\end{array}$ & $\begin{array}{l}<.0001 \\
<.0001 \\
<.0001 \\
0.0029\end{array}$ & $\begin{array}{l}1.032 \\
1.008 \\
1.069 \\
1.011\end{array}$ & $\begin{array}{l}(1.023,1.042) \\
(1.005,1.010) \\
(1.044,1.095) \\
(1.006,1.016)\end{array}$ & $\begin{array}{l}<.0001 \\
<.0001 \\
<.0001 \\
<.0001\end{array}$ \\
\hline $\begin{array}{l}\text { Secondhand } \\
\text { effects } \\
3 \mathrm{~km} \text { density } \\
3 \mathrm{~km} \text { density } \\
1 \mathrm{~km} \text { density } \\
1 \mathrm{~km} \text { density }\end{array}$ & $\begin{array}{l}\text { Off license } \\
\text { On license } \\
\text { Off license } \\
\text { On license }\end{array}$ & $\begin{array}{l}1.059 \\
1.015 \\
1.133 \\
1.020\end{array}$ & $\begin{array}{l}(1.028,1.091) \\
(1.006,1.024) \\
(1.035,1.240) \\
(1.008,1.032)\end{array}$ & $\begin{array}{l}0.0002 \\
0.0013 \\
0.0067 \\
0.0045\end{array}$ & $\begin{array}{l}1.057 \\
1.013 \\
1.113 \\
1.018\end{array}$ & $\begin{array}{l}(1.022,1.092) \\
(1.005,1.022) \\
(1.025,1.207) \\
(1.006,1.031)\end{array}$ & $\begin{array}{l}0.0011 \\
0.0020 \\
0.0107 \\
0.0045\end{array}$ \\
\hline
\end{tabular}

Note: Rate ratios shown are per 10 outlets.

* Since estimates were similar to those shown in Table 2, for sex, age, ethnicity and high school binge drinking, only density estimates, per 10 outlets, are given. The values for $3 \mathrm{~km}$ density are repeated for comparison. Rate ratios were computed using a GEE negative binomial model.

† For all other terms in the model 
On and off license outlets
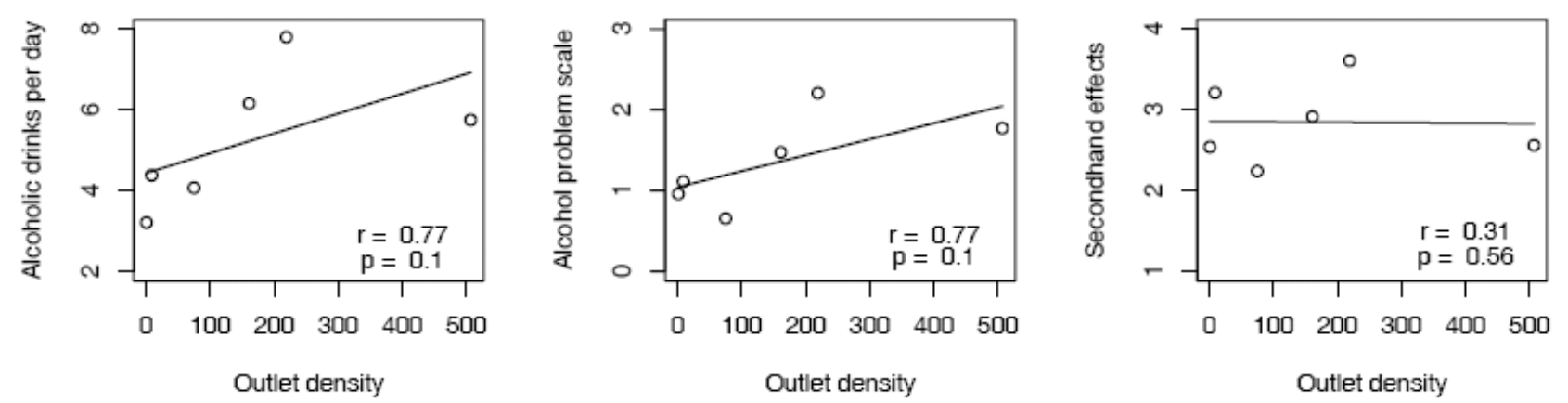

FIGURE 1-Three kilometre outlet density and (a) drinks per drinking day, (b) Alcohol Problems Scale, and (c) secondhand effects, in six university campus areas 